\title{
Environmental Awareness of Primary School-aged Children in Brisbane, Australia
}

\author{
Ruel Muldoon ${ }^{\text {a\#}}$, Tessa Shelford ${ }^{\text {a\#}}$, Olivia J Holland ${ }^{\mathrm{b}}$ and Deanne H Hryciw ${ }^{\mathrm{a}}$ \\ Corresponding author: Deanne Hryciw (d.skelly@ griffith.edu.au) \\ ${ }^{a}$ School of Environment and Science, Griffith University, Nathan, QLD, 4111 Australia \\ ${ }^{\mathrm{b}}$ School of Medical Science, Griffith University, Southport, QLD, 4222 Australia \\ \# equal first authors
}

Keywords: environment, primary school, children, awareness, survey, behaviour

International Journal of Innovation in Science and Mathematics Education, 27(2), 33-44, 2019

\begin{abstract}
Increased interest in conservation has led to an emerging interest in understanding children's environmental awareness. Consequently, an increase in environmental education as part of the curriculum in Australian primary schools has resulted. The awareness of students in Australian primary schools has not been extensively studied. Consequently, the aim of this study was to investigate the environmental awareness of primary school aged children, and if gender or age influences awareness. We surveyed 105 primary school students (66 girls, 39 boys; 9 to 12 years of age) from Brisbane, Australia. The survey consisted of 10 closed questions and two open questions about human impacts on the environment and food waste. There was no gender difference in the number of correct responses, and older students had more correct responses. Further, females were more likely than males to correctly answer questions focused on behaviour and its impact on the environment. Open questions identified broad global themes of human impacts on the environment, with students focusing on repurposing food waste rather than reducing the amount of food purchased as a way of managing food waste. Therefore, specific types of environmental awareness are observed in primary school aged children.
\end{abstract}

\section{Introduction}

Environmental awareness is defined as "the attitude regarding environmental consequences of human behaviour" (Ham, Mrčela, \& Horvat, 2015). Key to the development of environmental awareness is the i) development of personal awareness of the environment and one's connections to it, ii) development of an understanding of environmental concepts and knowledge of ecological, scientific, social, political and economic systems; and iii) the capacity to act responsibly upon what a person feels and knows in order to implement the best solutions to environmental problems (Staniforth \& Fawcett, 1994).

Environmental awareness has gained strength during the end of the 20th century, and associated with this is an increase in public demand for environmental issues to be addressed by the local and national governing authorities. There is a strong link between environmental issues and outcomes such as health, well-being and social structure within growing populations (Biggs \& Watmough, 2012), and environmental education is a tool for the development of a sustainable society (Alaydin, Demirel, Altin, \& Altin, 2014). Consequently, the environmental attitudes and perceptions of future generations are critical for the maintenance of natural resources (Korhonen \& Lappalainen, 2004). This has led to a related interest in children's direct 
understanding of the environment and an increase in environmental education programs in schools. Key to the successful provision of environmental education, is understanding and insight into children's attitudes towards environmental issues and how this is associated with their moral development (Littledyke, 2004). Interactions with the living environment in childhood is developed largely through social learning, and this is critical for the development of opinions on the environment (Littledyke, 2004).

A challenge in studying children's knowledge of the environment has arisen from the structure of the contemporary Western society (Chawla, 2007), as children may have limited direct experience with living systems, compared with children who grow up in agricultural or regional areas (Korhonen \& Lappalainen, 2004). Consequently, children in Western societies will develop much of their knowledge on environmental issues from sources such as parents and peers (Bishop et al., 2000). As environmental issues become heightened and create management concerns, there is an ever-growing need for a development in community awareness of these issues (Kaiser \& Scheuthle, 2003). Further, negative perceptions of the environment in childhood have the capacity to influence the understanding of environmental problems and concern in adulthood (Korhonen \& Lappalain, 2004).

A seminal paper in the field of environmental awareness demonstrated that children have a naturalistic attitude for nature and the environment, which is more developed in children than adults (Kellert, 1985). Further, Kellert identified that the most critical age for children's emotional concern about the environment was between 7 and 10 years of age (Kellert, 1985). In support of this, Bunting and Cousins (1985) identified that at approximately 11 years of age, children are highly committed to environmental preservation, compared to younger or older school aged children. Additional studies have investigated primary/middle grade school children's environmental awareness and their concerns for understanding ecological processes. Key to these analyses are the influence of age, gender and local residence (urban vs rural) (Cohen \& Horm-Wingerd, 1993). A limitation in these prior studies is that they have been performed a number of years ago, prior to the education of environmental issues by the media (Edwards, Skouteris, Rutherford, \& Cutter-Mackenzie, 2013). A previous study has demonstrated that media has a negative impact on environmental awareness, as it draws children away from experiences in nature and therefore to diminish their environmental awareness (Edwards et al., 2013). Therefore, students in the $21^{\text {st }}$ century may have a limited understanding about the environment due to the influences of the media. The study by Edwards et al. (2013) utilised focus group interviews, which may limit the expandability of this study to a wider context. Further, local aspects of environmental awareness we not discussed or surveyed as part of this study. Therefore, it is important to ensure that the residence environment is taken into consideration when understanding the environmental awareness of an individual (Cohen \& Horm-Wingerd, 1993). An additional key aspect to these studies is the use of age-appropriate methods of enquiry (Cohen \& Trostle, 1990).

Gender differences have been observed in the attitudes and concerns about environmental issues. In general, males have more technological knowledge about the environment, while females have stronger emotional responses concerned with environmental issues (Hunter, Hatch, \& Johnson, 2004). Certainly, a number of studies have shown that females are more concerned about the environment and have a higher environmental awareness (Tuncer, Ertepinar, Tekkaya, \& Sungur 2005). Edwards (2013) proposes that gender differences in environmental surveys is the result of perceived vulnerability to risk from the environment, so that females expressed a greater concern of environmental issues. Of note, it appears that the gender differences may be country specific, so that females are more environmentally 
concerned in Germany and the United States of America, while there was no gender differences in United Kingdom, Russia or Japan (Weaver, 2000).

The present study investigated the evidence of environmental awareness in primary school aged children in Australia. In line with the definition provided by Staniforth and Fawcett (1994), we defined environmental awareness via a personal awareness of the environment, an understanding of environmental concepts and knowledge of ecological, scientific, social, political and economic systems and the capacity to act responsibly when dealing with environmental problems. (Staniforth \& Fawcett, 1994). Further, based on previous literature, we sought to identify any influence of gender on environmental awareness. Our hypothesis was that school students aged 9 to 12 years of age in Australia would have a low level of environmental awareness (due to the media), with a significant difference in this awareness between females and males, and that older (grade 6 students) children would have a higher environmental awareness overall.

\section{Method}

Based on the previous studies, our research question was: Do school aged children in Brisbane, Australia have a high level of environmental awareness, so that age and gender are different in their level of awareness?

\section{Participants}

Ethical approval for this study was obtained from Griffith University Human Ethics Committee (Griffith University reference 2018/258). Primary school aged children, enrolled in Grade 5 and Grade 6 (9 to 12 years of age) at Our Lady of the Angels Primary School, Brisbane, Queensland, Australia participated in this study. Our Lady of the Angels Primary School is a medium size ( 600 students) school in a northern suburb of Brisbane, which is approximately 10 kilometres from the central business district of Brisbane. The social background is mixed, but the majority of the population are Caucasian, working-class families. Subjects were 105 children with 39 males and 66 females. Gender was self-identified.

\section{Design}

The survey was administered after written informed consent was obtained from the parents/guardians of the children. Surveys were administered by school teachers in the classroom setting, independent of the researchers. As no appropriate local environmental awareness surveys exist, a survey was developed to assess environmental awareness that consisted of three distinctive sections, using age-appropriate methods of enquiry (Cohen \& Trostle, 1990; Appendix 1). The survey was designed using material adapted from Toohey Forrest Environmental Education Centre resources (Toohey Forrest Environmental Education Centre, Department of Education Training and Employment facility, Griffith University EcoCentre, 2018). The survey consisted of: firstly, a section focused on personal demographic information, a second section consisting of two open questions i) Name a human impact that can damage our environment and why? ii) How can we reduce food waste in everyday households?), and a third section with 10 multiple choice questions containing four alternative answers each, with one correct response in each question (Appendix 1). Students were deemed to be environmentally aware if they achieved a score of $5 / 10$ for the multiple choice questions, with this awareness further characterised via open questions.

\section{Statistics}

All surveys were analysed using Excel (Microsoft) to quantify the demographic information and correct number of responses, separated by gender and grade. The 10 survey multiple choice 
questions were recorded as proportions, and Fisher's exact test $(\mathrm{p}<0.05)$ and odds ratios (in Graphpad Prism 7) were therefore used to compare the proportion of correct/incorrect answers for each question, separated by gender. Unanswered multiple choice questions were considered as incorrectly answered. The total proportion of each question answered correctly was compared between females and males using a paired t-test $(\mathrm{p}<0.05)$, after testing for normality using a D'Agostino and Pearson test (in Graphpad Prism 7). Discrimination index analysis was used to determine questions which could discriminate students who had mastered the knowledge (top $3^{\text {rd }}$ of cohort) compared with those who had not (bottom $3^{\text {rd }}$ of cohort).

\section{Results}

All students completed the survey and no surveys were deemed ineligible for inclusion in the study. Subject demographic data is summarised in Table 1. Overall, 63\% of students were female, and five spoke English as a second language (three females and two males). Most students lived within $4 \mathrm{~km}$ of the school, which indicates that they reside in a suburban residential area of northern Brisbane, Queensland.

Table 1: Student demographics

\begin{tabular}{c|l|l|l}
\hline School grade & Age (years) & Gender & English as a second language \\
\hline & $9: 1.9 \%$ & & \\
Year 5: $50 \%$ & $10: 58.7 \%$ & Male: $37.1 \%$ & Yes: $4.8 \%$ \\
Year 6: $50 \%$ & $11: 35.6 \%$ & Female: $62.9 \%$ & No: $95.2 \%$ \\
& $12: 3.8 \%$ & & \\
\hline
\end{tabular}

The average number of correct responses to the multiple choice questions was 6.541 out of 10 , with the median of 7 out of 10 (Figure 2 [see Appendix 2, p.12] and Table 2). There was no gender difference on the total number of correct responses between male and female students. There was a significant increase in the number of correct responses from students enrolled in grade 6 compared to grade $5(\mathrm{P}=0.0328 *)$.

Table 2: Percentage score of multiple choice questions (MCQs).

\begin{tabular}{l|c|c|c|c|c|c|c}
\hline $\begin{array}{l}\text { Number of MCQs answered } \\
\text { correctly (out of 10) }\end{array}$ & 3 & 4 & 5 & 6 & 7 & 8 & 9 \\
\hline $\begin{array}{l}(\%) \text { of children obtaining } \\
\text { this score }\end{array}$ & 2.9 & 6.7 & 11.4 & 24.8 & 29.5 & 19 & 5.7 \\
\hline
\end{tabular}

$\mathrm{MCQ}=$ multiple choice question

In questions $1,2,3,4,7,8,9$ and 10 (Figure 2), there was no significant difference between the number of correct responses for males and females. However, there was a significant difference between females and males in correct responses for questions 5 and 6 (Question 5: $\mathrm{P}=0.0046 * *$, Relative Risk $=1.815$, 95\% CI 1.196 to 2.946; Question 6: $\mathrm{P}=$ 0.0496*; Relative Risk $=1.146,95 \%$ CI 1.021 to 1.384: Figure 2E and Figure 2F), with females more likely to answer correctly in both instances (Question 5: females correct 65\%, males 
correct 36\%; Question 6: females correct 97\%, males correct 85\%; Figure 2). Overall questions, neither gender was more likely to answer correctly (mean correct: females $=67 \%$, males $=62 \%$ ). Discrimination index analysis (Figure 3) demonstrated that only question 1 and question 7 were not suitable to distinguish between students that have knowledge in this area of environmental awareness vs those who do not have knowledge in this area.

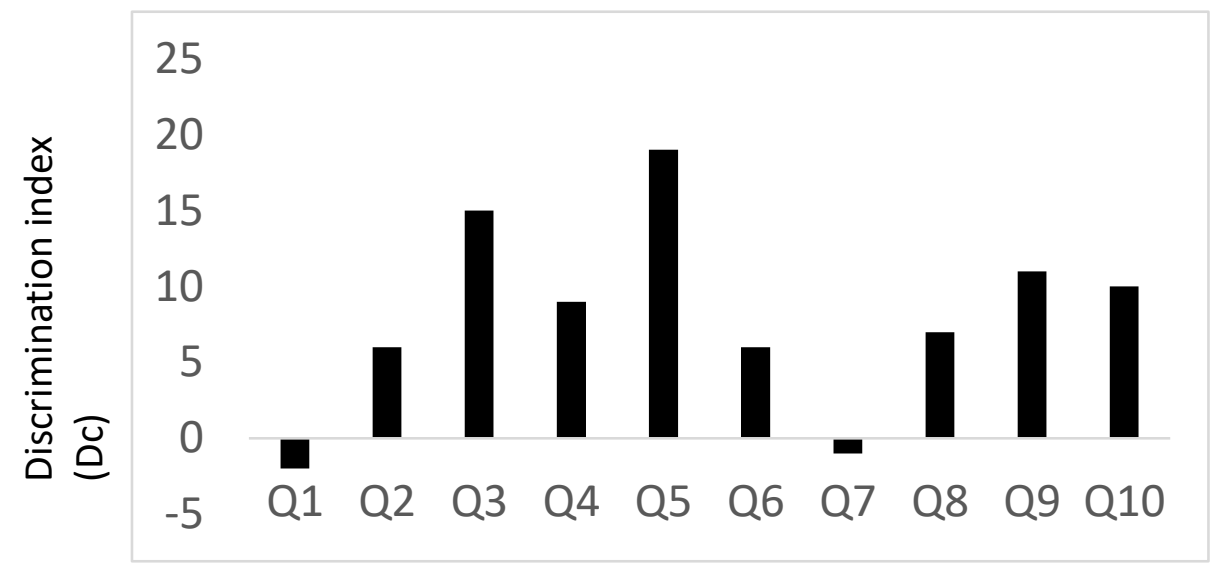

\section{Question number}

Figure 3: Discrimination index (Dc) for each multiple choice question. Dc is a measure of how well a question is able to distinguish between students who are knowledgeable and those who are not. Dc $>0$ indicates the question can discriminate.

All students provided written responses to the open questions (Table 3). Common themes identified in response to Question 1 (Name a human impact that can damage our environment and why) included deforestation, habitat loss and pollution. Of note, Brisbane is the closest capital city to the Great Barrier Reef, and students also commented on coral bleaching. A common theme identified in response to Question 2 (How can we reduce food waste in everyday households?) was using the excess food for compost or repurposing. Few students $(\sim 10 \%)$ indicated that reducing the amount of food purchased could be a mechanism for the reduction of food waste.

Table 3: List of common themes for questionnaire section

\begin{tabular}{|l|l|}
\hline $\begin{array}{l}\text { Q1. Name a human impact that can damage } \\
\text { our environment and why? }\end{array}$ & $\begin{array}{l}\text { Q2. How can we reduce food waste in } \\
\text { everyday households? }\end{array}$ \\
\hline - Plastic, does not break down & - Compost \\
- Deforestation & - Recycle \\
- Habitat loss & - Fertilizer \\
- Cars, fumes, fuel and carbon dioxide & - Freeze food \\
- Littering, pollution, rubbish in ocean & - Worm farms \\
- Killing sea animals & - Eat all your food/leftovers \\
- Not recycling & - Feed leftovers to pets \\
- Global warming & - Only buy food that you need \\
\hline
\end{tabular}




\author{
- Coral bleaching \\ - Damage ozone layer \\ - Landfill, putting rubbish in the wrong bin \\ - Coal mining, not renewable \\ - Fishing, nets \\ - Palm oil, orangutan habitat loss
}

\title{
Discussion
}

Environmental education and awareness is important as it affects the children's behaviour towards the environment. Here, a pilot study was undertaken to investigate environmental awareness of 105 students from grades 5 and 6 (ages 9 to 12 years) in a suburban primary school in a Queensland suburb. In general, we found that students have a good awareness of environmental issues and human impacts on the environment. Further, gender differences exist in students' knowledge concerning human behavioural influences on environmental change. Finally, older (grade 6) students had more environmental awareness than younger (grade 5) students. Of note, all students in this study were taught in composite classes, so that each individual class had grade 5 and 6 students learning together. This meant that students enrolled in grade 5 were exposed to the same content about the environment as students enrolled in grade 6 . Therefore, it is unlikely that exposure to the curriculum was a factor in the observed age differences in environmental awareness. Additionally, the survey tool developed here was effective at determining environmental awareness in school aged children, with discrimination indices indicating that 8 of the 10 multiple choice questions were able to be used to identify students with environmental awareness, in the context of their local environment.

One finding of interest is the gender differences observed in the attitudes and concerns about environmental issues. In this study, questions 5 and 6 were both on behavioural responses, requiring a specific directed action (recycling and composting), rather than general knowledge. For these questions, females were more likely to respond correctly. Prior research has suggested that females have stronger emotional responses concerned with environmental issues (e.g. Hunter et al., 2004). Our findings are supportive of the data from others, which demonstrate that females are more concerned about the environment (Tuncer et al., 2005), with females more aware of correct materials for recycling and composting. However, overall our findings disagree with the previous research which suggests that females have a generally higher environmental awareness (Tuncer et al., 2005), as there was no gender difference in the total number of correct responses. Another consideration of the outcome from this survey is that the questions that the females were more knowledgeable in the areas of recycling and composting, may be as female students are more involved and aware in household chores (unequally completed by female vs. male role models); and could relate to social gender roles rather than environmental sensitivity. Further investigation into this observation is warranted.

Age and environmental awareness have been reported to be linear, so that older children are more environmentally aware, with a peak at 11 years of age (Bunting \& Cousins, 1985). However, Ma and Bateson (1999) and Musser and Diamond (1999), identified the opposite, so that younger children were more aware of the environment. Our study demonstrated that the older (grade 6: 11 and 12 years old) students had more knowledge of the environment and human impacts. The reason for this may simply be time, where younger children have less 
experience and less knowledge base than older children (Aminrad, Sayed Zakaria, \& Hadi, 2011).

As part of this study, students identified human impacts on the environment, which largely focused on global issues such as waste, deforestation, habitat loss and pollution. The most common impact identified by students was litter, and its effects on the environment $(\sim 50 \%)$. For example, 1 student commented:

"When leaving rubbish on the ground it founds it's to the ocean and it's bad for the sea animals because they eat it" Grace, age 10

This demonstrated her identification of litter as a common impact, as well as its effect on the environment. Deforestation and habitat loss was also a common response ( 37\%). Of interest, students also commented on issues which were focused on their local region. For example, $\sim 12 \%$ students identified coral bleaching as a potential human impact on the environment. For example, 1 student commented:

\section{"Coral bleaching is killing the coral and is loosing [sic] colour" Georgia, age 11}

The Great Barrier Reef is found in Queensland, and approximately 2.68 million people (financial year 2016/2017) visit the reef each year. The Australian Government has pledged financial support for the projection of the reef, with an announcement one week following the completion of this survey of a package of \$500 million AUS to support reef conservation (Australian Government, Great Barrier Reef Marine Park Authority, 2018).

In addition, a multiple choice question (Q9) assessed students awareness of the removal of single-use plastic bags from the local supermarket chains in Queensland, Australia. Access to media may influence the knowledge of these students in local environmental issues, and this is supported by earlier studies which show that the students' "sense of place" (Hutchinson, 1998), reflected as "intimacy with the natural processes, community, and history of one's place" (Sanger, 1997, p. 4). More recent research has dampened the role of the media, so that the media has a negative impact on environmental awareness, as it draws children away from experiences in nature (Edwards et al., 2013).

Key to the discussion about the outcomes of this study, is the context by which primary school students are taught science in line with the Australian Curriculum: Science (Australian Curriculum, Assessment and Reporting Authority, 2018). In these grades (5 and 6), students must "describe and predict the effect of environmental changes on individual living things". The current survey formed part of a larger project, where students undertook a field excursion after the completion of the survey. However, there is no comprehensive school environmental education program and no specialist teachers focused on the environment. Much of the students' knowledge on environmental issues comes from parents and peers (Bishop et al., 2000). Researchers have identified that outdoor activities in the environment influence students' awareness and attitudes (Howe \& Disinger, 1988). The concern about this is that more students are engaging with the media which draws children away from experiences in the environment and thus affects their awareness (Edwards et al., 2013). Notably, for the group that participated in our study, no prior school based environmental engagement activity was undertaken before the completion of the survey. Further, compounded with the influence of the media, the outcomes from the survey may suggest that despite the limited exposure to the environment, the students' environmental awareness was not affected. In future, a study where students undertake the survey prior to and following an environmental engagement activity may be a way to assess the impact of the initiative. 
A limitation of this study is that a relatively restricted range of questions were asked. A broader survey, including questions concerning the students' source of environmental education, could add to the current data. Future analyses should determine the amount of environmental interaction that students have had, especially outside of the urban area. The administration of the survey occurred one week prior to an immersion activity where students investigated the effects of human impacts on the environment at a local creek catchment. Littledyke (2008) suggested that education is important for the development of pro-environmental behaviour. To investigate the reproducibility of the survey, future investigations should identify if long term behavioural change is affected by such interactions through administration of the same survey on more than one occasion.

\section{Conclusion}

In conclusion, this pilot study has demonstrated that general environmental awareness is evident in primary school aged children, with females more knowledgeable in the areas of recycling and composting, and older children possessing a higher level of awareness.

\section{References}

Alaydin, E., Demirel, G., Altin, S, \& Altin, A. (2014). Environmental knowledge of primary school students: Zonguldak (Turkey) example. Procedia-Social and Behavioural Sciences, 141, 1150-1155.

Aminrad, Z., Sayed Zakaria, S.Z.B., \& Hadi, A.S. (2011). Influence of age and level of education on environmental awareness and attitude: Case study on Iranian students in Malaysian Universities. Social Sciences, 6, 15-19.

Australian Curriculum, Assessment and Reporting Authority (2018). Science. Retrieved May 13, 2018 from https://www.australiancurriculum.edu.au/f-10-curriculum/science/\#

Australian Government, Great Barrier Reef Marine Park Authority (2018). Great Barrier Reef Partnerships for the future. Retrieved June 11, 2018 from http://www.environment.gov.au/system/files/resources/0e17f346a19f-411d-8a60-59bd2b0fee27/files/reef-partnerships-future-new.pdf

Biggs, E.M., \& Watmough, G.R.R. (2012). A community-level assessment of factors affecting livelihoods in Nawalparasi Distrct, Nepal. Journal of International Development, 24(2), 255-263.

Bishop, K., Reid, A., Stables, A., Lencastre, M., Stoer, S., \& Soetaert, R. (2000). Developing Environmental Awareness through Literature and Media Education: Curriculum Development in the Context of Teachers' Practice. Canadian Journal of Environmental Education, 5(1), 244-286.

Bunting, T.E., \& Cousins, L.R. (1985). Environmental dispositions among school-aged children: A preliminary investigation. Environment and Behaviour, 17(6), 725-768.

Chawla, L. (2007). Childhood experiences associated with care for the natural world. Children, Youth and Environments, 17(6), 144-170.

Cohen, S., \& Horm-Wingerd, D. (1993). Children and the environment: Ecological awareness among preschool children. Environment and Behavior, 25(1), 103-120.

Cohen, S., \& Trostle, S.L. (1990). Young children's preferences for school-related physical-environmental setting characteristics. Environment and Behavior, 22(6), 753-766.

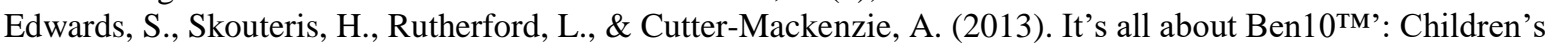
play, health and sustainability decisions in the early years. Early Child Development and Care, 183(2), 280-29.

Ham, M., Mrčela, D., \& Horvat, M. (2016). Insights for measuring environmental awareness. Journal of Ekonomski Vjesnik/ Econviews, 29(1), 159-176.

Howe, R.W., \& Disinger, J.F. (1988) Teaching environmental education using out-of-school settings and mass media. Environmental Education Digest (1). http://www.ericdigests.org./pre-9215/mass.htm

Hunter, L.M., Hatch, A., \& Johnson, A. (2004). Cross-national gender variation in environmental behaviors. Social Sciences Quarterly, 85(3), 677-694.

Hutchison, D. (1998). Growing up green: Education for ecological renewal. New York and London: Teachers College, Columbia University. 
Kaiser, F.G., \& Scheuthle, H. (2003). Two challenges to a moral extension of the theory of planned behaviour: Moral norms and just world beliefs in conservationism. Personality and Individual Differences, 35(5), 1033-1048.

Kellert, S.R. (1985). Attitudes toward animals: Age-related development among children. The Journal of Environmental Education, 16(3), 29-39.

Korhonen, K., \& Lappalainen, A. (2004). Examining the environmental awareness of children and adolescence in the Ramomafana region, Madagascar. Environmental Education Research, (10)2, 195-216.

Littledyke, M. (2004). Primary children's' views on science and environmental issues: Examples of environmental cognitive and moral development. Environmental Education Research, 10(2), 217-235.

Littledyke, M. (2008) Science education for environmental awareness: approaches to integrating cognitive and affective domains. Environmental Education Research, 14(1), 1-17.

Ma, X., \& Bateson, D.J. (1999). A multivariate analysis of the relationship between attitude toward science and attitude toward the environment. The Journal of Environmental Education, 31(1), 27-32.

Musser, L.M., \& Diamond, K.E. (1999). The children's attitudes towards the environment scale for preschool children. The Journal of Environmental Education. 30(2), 23-30.

Sanger, M. (1997). Sense of place and education. Journal of Environmental Education, 29(1), 4-10.

Staniforth, S., \& Fawcett, L. (1994). Metamorphosis for environmental education: A core course guide for primary / elementary teacher training. The Commonwealth of Learning: Vancouver, BC/ UNESCO.

Toohey Forrest Environmental Education Centre (2018). Retrieved March 12, 2018 from http://tooheyforesteec.eq.edu.au/documents/

Tuncer, G., Ertepinar, H., Tekkaya, C., \& Sungur, S. (2005). Environmental attitudes of young people in Turkey: Effects of school type and gender. Environmental Education Research, 11(2), 215-233.

Weaver, A.A. (2002). Determinants of environmental attitudes. International Journal of Sociology, 32(1), 77 108. 


\section{Appendix 1: Multiple choice questions administered to the children}

Please circle the most correct answer

1. What is most common type of natural disaster?

a) earthquake

b) bushfire

c) volcano eruption

d) flood

2. What is the biggest threat to animal populations worldwide?

a) habitat loss

b) hunters and poachers

c) natural disasters

d) disease

3. What is an extinct species?

a) a species that is in danger of dying out completely

b) a species that has died out completely

c) a species that is sick

d) a species that is rare

4. Which of the following is a renewable resource?

a) oil

b) iron ore

c) trees/timber

d) coal

5. Which one of these items does not go in the recycling bin?

a) coke can

b) broken glass

c) plastic chip packet

d) egg carton

6. Which of the following is the most correct thing to put into a compost bin?

a) milk bottles

b) apple core

c) paper

d) old clothes

7. What's the most common type of rubbish found in the ocean?

a) glass

b) plastic

c) waste from boats

d) aluminium cans

8. How much of the earth's fresh water is available for human use?

a) $\quad 97 \%$ 

b) $3 \%$
c) Less than $1 \%$
d) $25 \%$

9. When will a ban on single-use plastic bags in Queensland (Australia) shopping centres be introduced?
a) $\quad 2019$
b) $\quad 2050$
c) Never
d) July 2018

10. What is the current world population?
a) 5 billion
b) $\quad 10.2$ billion
c) 7.3 billion
d) 9.4 billion 


\section{Appendix 2: Figure 2}

A

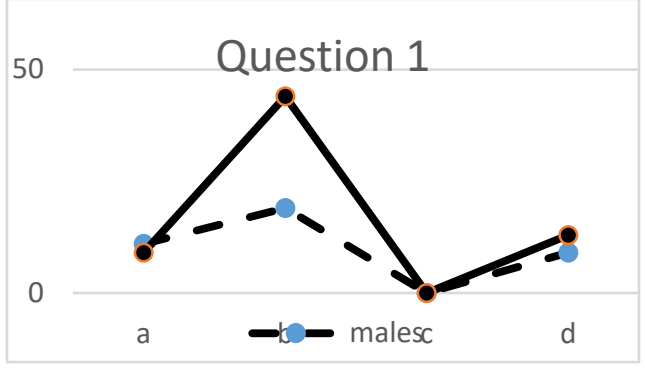

$\mathrm{C}$

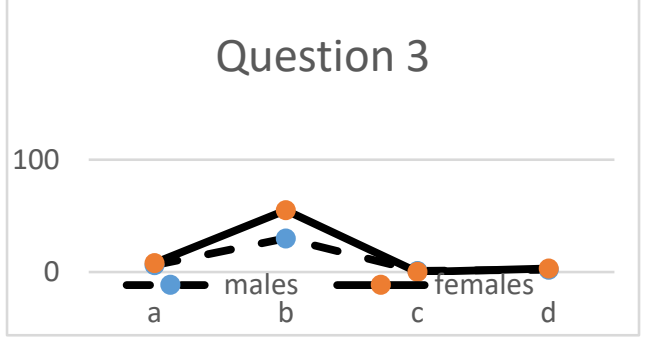

$\mathrm{E}$

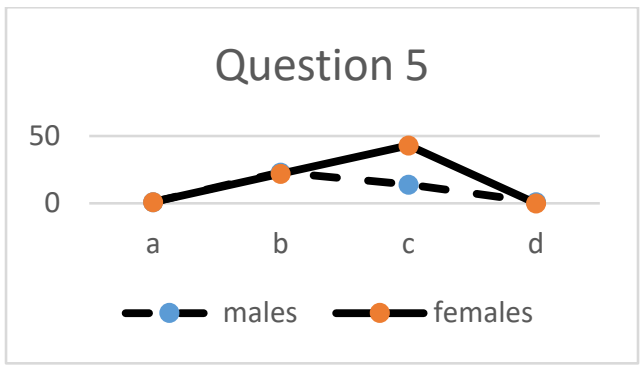

G

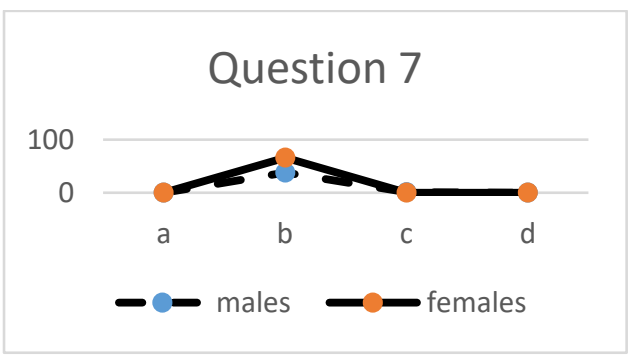

I

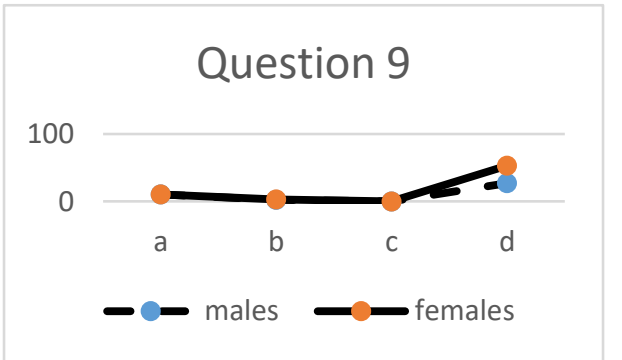

B

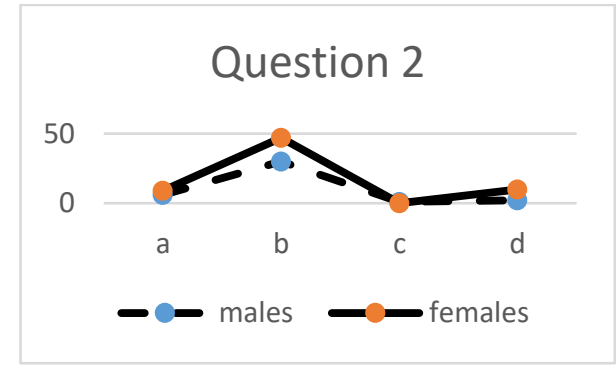

$\mathrm{D}$

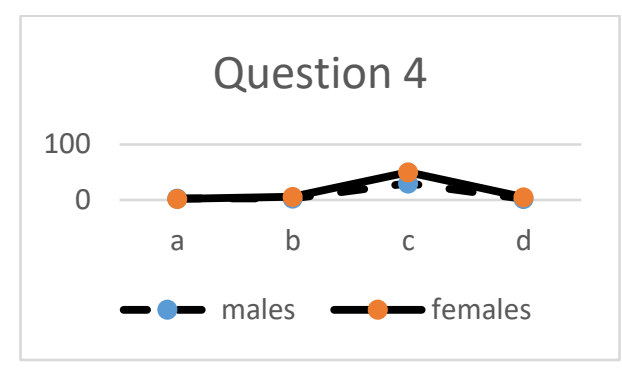

$\mathrm{F}$

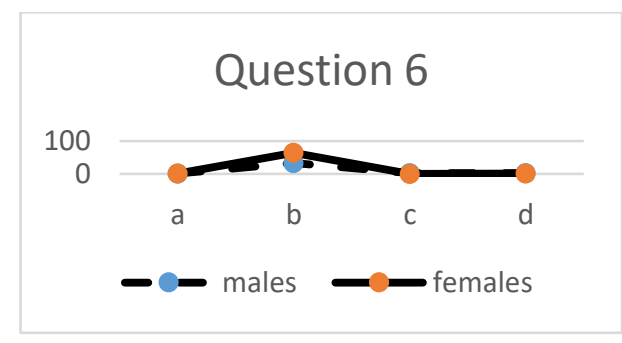

$\mathrm{H}$

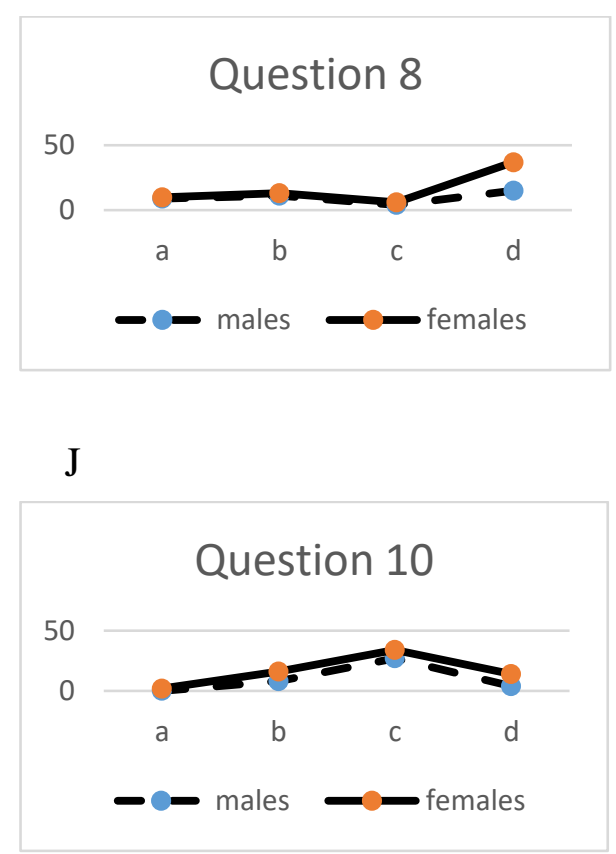

Figure 2: Correct responses to multiple choice questions separated by gender. Males $n=39$ (dashed line), females $n=66$ (solid line). 